Int. J. Electrochem. Sci., 14 (2019) $3291-3300$

International Journal of

ELECTROCHEMICAL

SCIENCE

www.electrochemsci.org

Short Communication

\title{
Synthesis of Au@PtAuAg Yolk-Shell Nanoalloy as an Electrocatalyst for Methanol Oxidation Reaction
}

\author{
Zirong $\mathrm{Li}^{1, *}$, Jiajing $\mathrm{Li}^{2}$, Zhenghua Wang ${ }^{2, *}$ \\ ${ }^{1}$ College of Chemistry and Materials Engineering, Anhui Science and Technology University, Bengbu, \\ Anhui, China, 233000 \\ ${ }^{2}$ College of Chemistry and Materials, Anhui Normal University, Wuhu, Anhui, China, 241000 \\ *E-mail: $\underline{\text { lizir@ahstu.edu.cn }}$
}

doi: $10.20964 / 2019.04 .55$

Received: 1 January 2019 / Accepted: 9 February 2019 / Published: 10 March 2019

Au@PtAuAg yolk-shell nanoalloy composed of an Au nanoparticle core and a PtAuAg shell was synthesized via a simple wet-chemical method. The Au@PtAuAg nanoalloy was applied as an electrocatalyst for methanol oxidation reaction, and it shows a good electrocatalytic activity and better anti CO poison ability than that of commercial Pt/C catalysts. The better electrocatalytic performance of the Au@PtAuAg yolk-shell nanoalloy was possibly due to the electronic effect by Au and Ag that could facilitate the elimination of the intermediate during methanol oxidation.

Keywords: yolk-shell nanoalloy; Au@PtAuAg; methanol oxidation

\section{FULL TEXT}

(C) 2019 The Authors. Published by ESG (www.electrochemsci.org). This article is an open access article distributed under the terms and conditions of the Creative Commons Attribution license (http://creativecommons.org/licenses/by/4.0/). 